\section{Forgotten Surgical Gauze: A Rare Cause of Recurrent Perianal Fistula}

Sir,

Suppurative perianal conditions are expected to be eradicated by surgery, but $30 \%$ fistulae may recur. ${ }^{1}$ Tuberculosis, Crohn's disease, or tumors may lead to recurrence ${ }^{2,3} \mathrm{~A}$ forgotten surgical gauze, used for packing of the perianal abscess cavity after surgery for perianal fistulae, is a rare cause of the recurrence, which, to our knowledge, has not been described in literature.

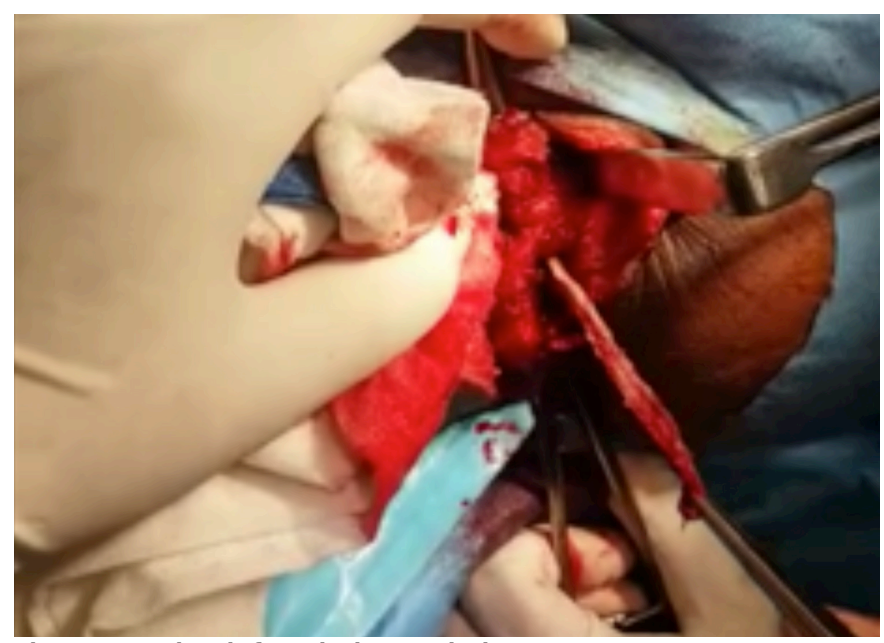

Figure 1: Retrieval of surgical gauze during surgery.

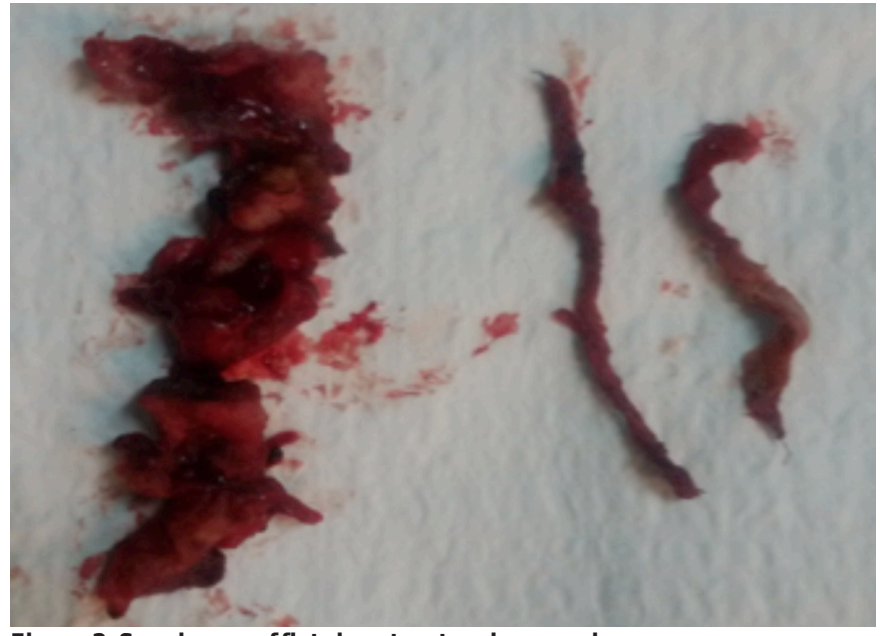

Figure 2: Specimens of fistulous tract and guaze pieces.

A 70-year diabetic male patient presented in Surgical Outpatient Department in our hospital in July, 2016 with recurrent perianal fistula after a previous surgery eight months ago. Local examination revealed two perianal openings at 5 and 9 O'clock position along with a visible scar mark from previous surgery at 7 O'clock position. Proctoscopy did not reveal any internal opening. A fistulogram showed contrast collection in left perianal region, likely representing an abscess formation with cutaneo-cutaneous fistula. After preparation, surgery was performed under spinal anesthesia. Dissection of the tract led to an abscess cavity, which contained two gauze pieces, each measuring $5 \mathrm{~cm}$ (Figures 1 and 2). The cavity was curetted and wall biopsy taken for histopathology. The opened up abscess cavity was packed after thorough irrigation. Next day, the pack was removed and the patient was discharged with advice of regular sitz bath. Histopathology turned out to be chronic inflammatory reaction with granuloma formation with birefringent foreign bodies, linked to gauze wreckage. The wound healed completely in six weeks after surgery. The patient remained asymptomatic up to one yearfollow-up.

Packing the abscess cavity with surgical gauze is a common practice to achieve hemostasis and prevent approximation of skin margins. ${ }^{4,5}$ Finding a gauze in the recurrent perianal fistula was an incidental finding. The routine investigation, fistulogram, performed in this case, could not pick up a retained guaze in perineal region. A three-dimensional endoanal ultrasound and MRI might have picked up the gauze, which however, were not done in this case due to affordability issues. ${ }^{4,5}$ The odds of forgetting gauze in this particular case may be related to very small size of the gauze pieces (approximately $5 \mathrm{~cm}$ length).

Counting the numbers of gauze pieces, using long gauzes and careful inspection of abscess cavity by surgeon may prevent this problem.

\section{CONFLICT OF INTEREST:}

The author declared no conflict of interest.

\section{PATIENT'S CONSENT:}

Informed consent was obtained from the patient.

\section{AUTHOR'S CONTRIBUTION:}

As it is a solo-written letter, so all aspects are contributed by the author.

\section{REFERENCES}

1. Hasan A, Evgenikos N, Daniel T, Gatongi D. Filshie clip migration with recurrent perianal sepsis and low fistula in ano formation. BJOG 2005; 112:1581.

2. Dua RS, Dworkin MJ. Extruded Filshie clip presenting as an ischiorectal abscess. Ann R Coll Surg Engl 2007; 89(8): 808-9. doi:10.1308/003588407X232170.

3. Byrne CM, Lim JK, Stewart PJ. Ischiorectal abscess caused by ingested bones. ANZJ Surg 2004; 74(9):818-9.

4. Paksoy M, Ozben V, Ayan F, Simsek A. An atypical etiology of suprasphincteric fistula: A forgotten surgical material. Case Rep Med 2010; 2010:189846. doi: 10.1155/2010/ 189846.

5. Tonkin DM, Murphy E, Brooke-Smith M, Hollington P, Rieger $\mathrm{N}$, Hockley S, et al. Perianal abscess: A pilot study comparing packing with nonpacking of the abscess cavity. Dis Colon Rectum 2004; 47:1510-4. 


\section{Muhammad Saad Faisal}

Department of General Surgery, Sharif Medical \& Dental College, Raiwind Road, Lahore, Pakistan

Correspondence to: Dr. Muhammad Saad Faisal, Depart- ment of General Surgery, Sharif Medical \& Dental College, Raiwind Road, Lahore, Pakistan

E-mail: ahlaparoscopicclinic@gmail.com

Received: January 08, 2020; Revised: March 13, 2021;

Accepted: April 24, 2021

DOI: https://doi.org/10.29271/jcpsp.2021.08.1007 